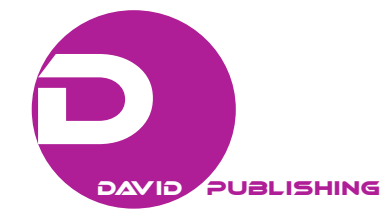

\title{
Crop Yield Estimation with Farmers’ Appraisal on Weather Condition
}

\author{
Jean Baptiste HABYARIMANA \\ Agriculture Statistician \\ Ministry of Agriculture and Animal Resources \\ Kigali, Rwanda
}

\begin{abstract}
Crop yield is mainly affected by weather condition, inputs, and agriculture policies. In the crop yield estimation, farmers' perception on weather conditions lead to the assessment of how well yield would be compared to the previous seasons. This paper applies Bayesian estimation method to estimate crop yield with farmers' appraisal on weather condition. The paper shows that crop yield estimation with farmers' appraisal on weather condition takes into account risk proportionally to climate change. In light of the United Nations efforts aimed to build a consolidated agriculture statistical system across countries, the statistical model developed here should provide an important tool both for the crop yield estimation and food price analysis.
\end{abstract}

Key words: Crop Yield Estimation, Farmers' Appraisal on Weather Condition, Crop growing condition, Bayesian Estimation Method

\section{Introduction}

Land productivity is a vital factor in feeding the population. It is also a critical factor in the struggle of developing countries to improve the availability of food. In line with MDGs, developing countries have undertaken different measures to improve land productivity. Following all those policies the main challenge for agriculture statistician in many developing countries remains to be the development of statistical models that could provide reliable crop yield estimates with high exactitude to monitor and assess the progress of agricultural land productivity. This study undertakes this task to offer a method complementary to those available in the literature such as crop cutting and famers' estimate.

\section{Literature Review}

In most of the cases, yield forecasts are based on reports by crop correspondents at regular intervals during the growing season using crop appearance as an indicator. In this context, the most accurate method of estimation consists of crop cutting method" (G.R. Spinks).

Thus, crop condition data has the potential to provide a simple, regular source of information about the realized yield. In addition, weather affects crops differently during different stages of crop growth (Ranjana Agrawal, 2012).

Corresponding author: Jean Baptiste HABYARIMANA, Agriculture Statistician, Ministry of Agriculture and Animal Resources, Kigali, Rwanda. E-mail: kradrimn@gmail.com. 
To overlook the impact of weather condition on crops growing and yields, Stasny, Goel and other researchers at the Ohio State University developed a Bayesian mixed-effects county yield estimation algorithm with a spatial component involving correlations among neighboring counties (Michael E. Bellow, 2007). In addition to this, Bayesian probability approach of obtaining yield forecasting involves the collection of expert opinion data of farmers who are actually engaged in raising the crop regarding their assessments about the likely crop production (Chandrahas).

\section{Estimation Method}

Drawing on the crop yield forecasting and estimation literature, crop yield is a function of weather condition, inputs and agro-ecological conditions including weather, land and external input use. To cover the gap between crop yield and risk resulting from climate change, this paper models crop yield as a function of weather and crop growing conditions (appearance) subjected to farmers' information on weather.

\section{Statistical Model}

From a Bayesian standpoint, true model parameters were unknown and therefore considered to be random, and they were assigned a joint probability distribution. Prior distribution was used to summarize our state of knowledge, or what is currently known about the parameters. Once the data were observed, the evidence provided by the data was combined with the prior distribution using Bayes' Theorem. The result of combining prior information and empirical evidence was an updated posterior distribution for the parameters.

In this context, four piece of information was used "actual yield, yield targets, realized performance towards yields targets, and farmers' appraisal on weather condition". Those pieces of information were also used to estimate variance and covariance information on yield. In the empirical example for model illustration six crops were considered when trying to forecast yields.

In the first stage of parameter estimation, average yields " $y_{f j}$ " was computed using actual yields of Maize, Rice, Beans, Cassava, Irish Potatoes, and farmers' appraisal on weather conditions:

Box 1

$$
\begin{gathered}
y_{f j}=\frac{\sum_{i=1}^{4} y_{i j} \omega_{i j} c_{i k}}{\sum_{i=1}^{4} \omega_{i j} c_{i k}} \\
\text { Where } \omega_{i j}=y_{i j} * p_{i j} \text { and } p_{i j}=\frac{y_{i j}}{\sum_{i=1}^{4} y_{i j}}
\end{gathered}
$$

Where $y_{i j}=\{1,2,3,4 \mid$ yield values for four percentiles dividing actual yields into five equal groups $\}$ for crop j = Maize, Rice, Wheat, Beans, Cassava, and Irish Potatoes. Four scales weather conditions are denoted by $k=$ Poor, Fair, Good, Very Good; and $\omega_{i j}=$ expected yield in each scale for crop " $j$ ". Weather conditions " $C_{i k}$ " are associated with actual yield $y_{i j}$ by $C_{i k}$ with $\left\{C_{i k}=\{1=\right.$ Poor, $2=$ Fair, $3=$ Good, $4=$ Very Good $\mid i$ percentile is linked with its corresponding $\mathrm{k}$ weather condition $\}$.

In the second stage, actual performance to reach yield targets for each crop " $j$ " " $R_{j}$ " was computed using average yields " $y_{f j}$ " and yield targets " $y_{t j}$ "

Box 2

$$
R_{j}=\frac{y_{f j}}{y_{t j}}
$$

In the third stage, average yields " $y_{f j}$ ", yield targets $Y_{t j}$ and actual yield performance $R_{j}$ and their associated reliabilities were used to estimate covariance and variance information on yields. 
To develop Bayesian methods for generating yield estimates from readily available crop and weather conditions information; it was assumed that average yield are normally distributed " $d_{1} \mid x^{1} \sim N_{p}\left(D_{1} x^{1} \Sigma_{1}\right)$ " and that posterior distribution of yields is given by $x^{1} \mid d_{1} \sim N_{n}(\mu ; V)$ " where $\mu_{t+1}=$ Estimated average yield and $V=$ Variance.

$$
\begin{aligned}
& \left.\mu=\left(A^{+} H A^{+T}\right) D^{\mathrm{T}}{ }_{1} \Sigma^{-1} d 1\right) \text { and } \\
& V=A^{+} H A^{+\mathrm{T}}-A^{+} H A^{+T} D^{T}{ }_{1} \Sigma^{-1} D 1 A^{+} H A^{+T} \\
& A^{+}=A^{T}\left(A A^{T}\right)^{-1} \text { "Moore-Penrose inverse" } \\
& \text { and } \Sigma_{0}=\Sigma_{1}+D 1 A^{+} H A^{+T} D^{T} \text {. } \\
& \text { (see Theorem } 1 \text { in Magnus, Tongeren and Vos (2000). }
\end{aligned}
$$

\section{Case study Development}

Agriculture sector is predominant in Rwanda and the Government of Rwanda has invested a lot in agriculture sector by introducing new seed varieties, reinforcing the use of chemical fertilizers and pesticides, soil management and land rehabilitation, anti-erosion activities, farmers field school, etc.. But controversially, Rwanda experiences food prices fluctuation over time. Hence, as growing season forecasts of crop yields are of considerable interest to commodity market participants and price analysts, the main problematic issue remains to be the development of consistent method with compatible predicting statistical model able to make yield estimations with much higher precision to explain those controversial phenomena.

The yields data for empirical illustration used in this paper came from Crop Assessment Surveys.

This paper hypotheses that Bayesian estimation method that consider past information on crop yields, present farmers' knowledge on weather conditions and present agro-ecological information could provide a simpler and peerless complementary statistical model to estimate crop yield.

\section{Results and Discussion}

Farmers' problem is an optimization problem in which estimated yield should be close to forecasted yields as possible. The optimization problem shows that:

(1) The expected yields are less than average of yields recorded in 22 past seasons;

(2) Forecasted yields are less than the average of yields of two latest previous seasons;

(3) Estimated yields are greater than average of yields recoded in 22 past seasons.

(4) The final results show that the estimated crop yields tend to deviate from the forecasted crop yields by the mean of yields recorded in 22 past seasons.

\section{Descriptive Statistics}

Table 1 shows descriptive statistics "Mean yield ( $\mathrm{Kg} / \mathrm{Ha})$, Standard deviation, Minimum and maximum yields $(\mathrm{Kg} / \mathrm{Ha})$ realized in 11 past years with 22 observations".

Figure 1, shows the trends (2002 to 2012) of Maize, Wheat, Rice, Beans, Irish Potato and Cassava yields. Trends show an overtime increase of yields for all crops considered.

\section{Crop Yield Estimates}

The final results showed in table 2 revealed that when estimated yields for 2013 Agriculture year are compared to actual yields realized in 2012 Agriculture Season; yield (Kg/Ha) for Maize, Wheat, Rice, Irish Potato, and Cassava and Beans could increase if the weather condition does not change or change slightly as it was appraised by farmers. 
Table 2 shows that expected yield are less than the mean of actual yields. The mean of actual yields are less than forecasted yields. Forecasted yield are less than estimated yields.

Table 1

Descriptive Statistics

\begin{tabular}{llllll}
\hline Variable & Obs & Mean & Std. Dev. & Min & Max \\
\hline maize & 22 & 1264 & 717 & 559 & 2820 \\
wheat & 22 & 1096 & 598 & 377 & 2208 \\
rice & 22 & 4020 & 1063 & 1890 & 5751 \\
beans & 22 & 837 & 190 & 500 & 1101 \\
iris potato & 22 & 8003 & 2241 & 5409 & 12605 \\
cassava & 22 & 9093 & 3135 & 5177 & 13974 \\
\hline
\end{tabular}

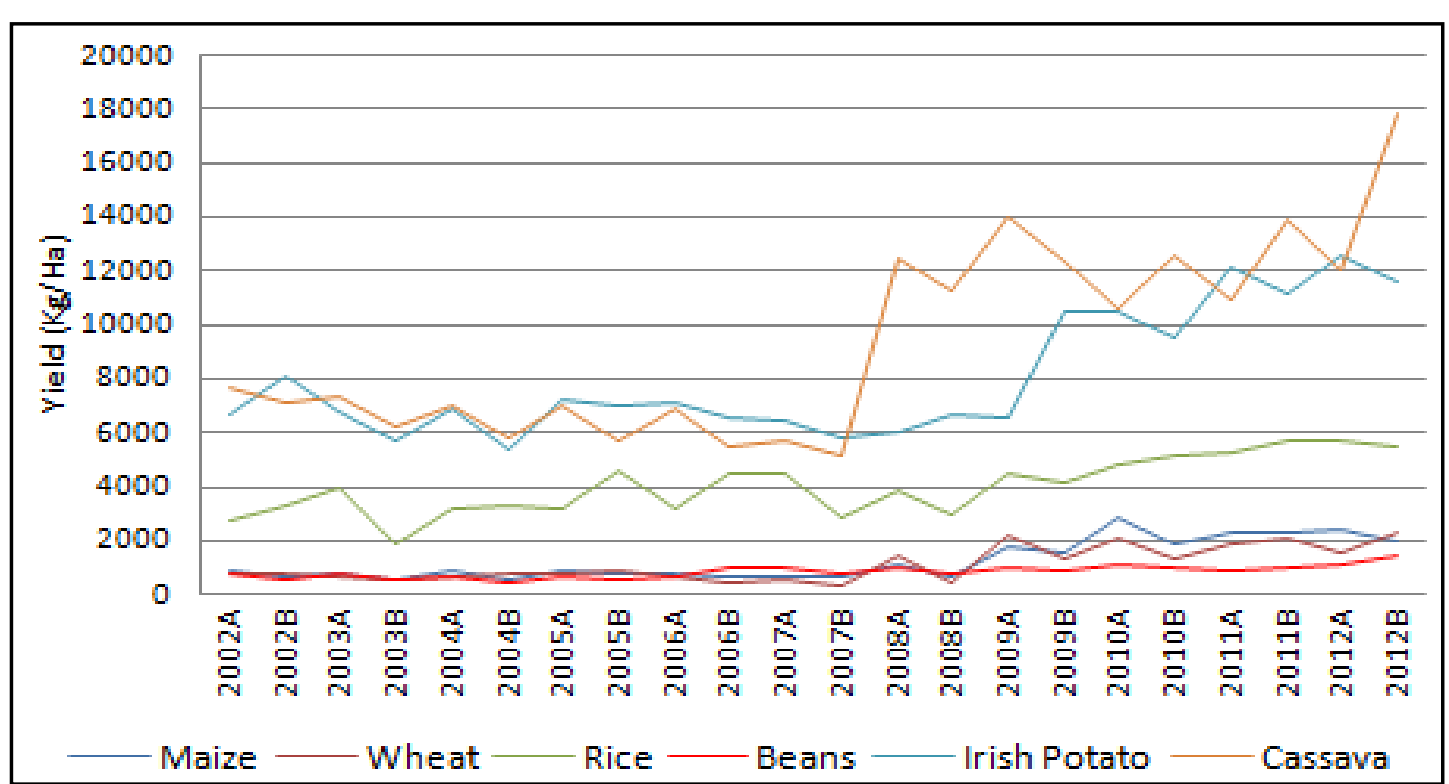

Figure 1. Trend of Crop Yield over last 11 Years.

Table 2

Crop Yields Estimates

\begin{tabular}{lllllll}
\hline & Maize & Wheat & Rice & Beans & Irish Potato & Cassava \\
\hline $\mathrm{Y}_{\mathrm{j}}=$ Actual Yields (2002-2012) & 1,260 & 1,125 & 4,031 & 855 & 8,055 & 9,326 \\
$\mathrm{G}_{\mathrm{j}}=$ Expected Yields & 1,123 & 1,118 & 3,378 & 701 & 6,497 & 7,847 \\
$\mathrm{Y}_{2012}=$ Actual Yields & 2,186 & 1,916 & 5,597 & 1,265 & 12,115 & 14,934 \\
$\mathrm{Y}_{\mathrm{tj}}=$ Targeted Yields ${ }^{1}$ & 3,750 & 3,500 & 7,000 & 1,850 & 27,500 & 35,000 \\
$\mathrm{Y}_{\mathrm{fj}}=$ Forecasted Yields & 1,459 & 1,440 & 3,980 & 829 & 7,809 & 9,417 \\
$\mathrm{Y}_{\mathrm{ej}}=$ Estimated Yields for 2013A & 2,934 & 2,889 & 5,878 & 1,397 & 17,793 & 22,965 \\
\hline
\end{tabular}

\section{Assessment of the progress of agricultural land productivity}

To assess the progress of land productivity to feed population and make available food at markets, performances were computed as the basis of crop yield monitoring. i) Performance with forecasted yields that

\footnotetext{
${ }^{1}$ Yields collected in Rwanda Agriculture Agenda "Agenda Agricole"
} 
combines past information, states what was the performance to reach targeted yields by the time of setting those targets; ii) Actual performance was computed referring to the average yields of the latest two agriculture seasons to state how far agriculture households were to reach targeted yields in 2012; iii) Performance with estimated yields was computed referring to the estimated yields and targeted yields to state how far agriculture households should be to reach targeted yields in 2013.

Table 3

Land productivity assessment

\begin{tabular}{lllllll}
\hline & Maize & Wheat & Rice & Beans & Irish Potato & Cassava \\
\hline $\mathrm{R}_{\mathrm{j}}=$ Performance with Forecasted Yield & $39 \%$ & $41 \%$ & $57 \%$ & $45 \%$ & $28 \%$ & $27 \%$ \\
Actual Performance & $67 \%$ & $75 \%$ & $71 \%$ & $66 \%$ & $64 \%$ & $63 \%$ \\
Performance with Estimated Yield & $78 \%$ & $83 \%$ & $84 \%$ & $76 \%$ & $65 \%$ & $66 \%$ \\
\hline
\end{tabular}

Performance ratios derived from the model formulated using prior information and empirical evidences could in meaningful way be used in land productivity and food market price analyses. Performance ratios could also describe the relationship between agriculture production on one hand and the effort made to improve land productivity such us introduction of new seeds varieties; use of fertilizers and pesticides; soil management and extension services on the other hand. The used model could play an important role when analyzing the impact of climate change on agriculture sector and the effort made to face the problem of climate change.

\section{Policy Implication}

The estimation model developed in this paper could help decision takers and policymakers: i) To monitor land productivity and yield targets; ii) To link crop yield and crop production; iii) To monitor food availability, food demand and market access when assessing food shortage and planning for food redistribution"; iv) To link weather condition a constraints to land productivity and food availability with meaningful early warnings to lower crop production risks and ensure public awareness and preparedness to act; v) To correlate food prices with agriculture production and climate change.

\section{Concluding Remarks}

This paper develops predicting statistical model laying on Bayesian Method. The developed Statistical model for crop yield estimation could contribute to the development and credibility of agricultural statistics. This paper comes with new insights and paves the way for agricultural policy analysis by providing timely high precision, credible and compatible yield estimates that could lead to reliable crop production estimation. As crop yields have significant impact for both commodity prices and farmer income, growing season estimates of crop yields provided by this model could be of considerable utilization to price and food security analysts.

\section{Acknowledgements}

I wish to express my profound gratitude to Dr. Temel Tugrul senior researcher, Mr. Enock Chinganda senior expert in statistics, Birasa Nyamulinda lecturer at National University of Rwanda, and Mrs Francine UWAYO agricultural statistician at MINAGRI who provided technical advices. Their comments and guidance were very useful to the study. The errors in this paper, however, are the author's and neither Government Institutions nor Non-Government Institutions is responsible for them. 


\section{References}

Alpha C. (1984) Chiang. Fundamental Methods of Mathematical Economics. Third Edition. USA.

Carl P Simon and Lawrence Blume. (1994) Mathematics for Economists. First Edition. USA.

Chandrahas, Bayesian Probability Approach for Crop Yield Forecasting. Indian Agricultural Statistics Research Institute, New Delhi-110012).

Fryzlewicz, P., Van Bellegem, S. \& von Sachs. (2003) Forecasting non-stationary time series by wavelet process modelling. Annals of the Institute of Statistical Mathematics.

G.R. Spinks. Uses and Methods of Crop Forecastin.

Kruse, John R. and Darnell Smith. "Yield Estimation Throughout the Growing Season." In Applied Price Analysis, Forecasting, and Market Risk Management, Proceedings of the NCR-134.

Magnus, J. R., van Tongeren, J., and Vos. (2000) National accounts estimation using indicator ratios. Review of Income and Wealth, Series 46, No. 3, p-329-350.

Michael E. Bellow. (2007) Comparison of Methods for Estimating Crop Yield at the County Level.

Paul L. Fackler and Bailey Norwood, Forecasting Crop Yields and Condition Indices.

R. Davidson and J.G. MacKinnon. (1993) Estimation and Inference in Econometrics. Oxford University Press, Oxford.

Ranjana Agrawal. (2012) Forecasting Techniques in Crops. New Delhi.

Vladimir Rakocevic, On continuity of the moore-penrose and drazin inverses, Math. P: 163-172

USDA. (1998) "Crop Progress/Crop Weather: Terms and Definitions." National Agricultural Statistics Service \{NASS), Washington.

USDA. Crop Production. National Agricultural Statistics Service (NASS), Washington. Monthly.

\section{Annexes}

\section{Methodology}

To perform Bayesian Estimation Method for Crop yield forecasting, five matrixes $\mathrm{d}_{6 \times 1}$ Matrix of Targeted yields, [ $D_{6 \times 12}=$ $\left.\left(I_{6 \times 6} 0_{6 \times 6}\right)\right]$ Matrix for Crops to be used in yield forecasting, $A_{12 \times 12}$ Matrix of Actual level to reach targeted Yield " $Y_{t j}$ ", Variance Matrix $\left(E_{1}\right)$, Covariance Matrix $(H)$ were estimated and used in the Bayesian Estimation Model. The matrices dimensions follow the number of crop which we want to estimate their yield. In the empirical example for model illustration six crops were considered which yield estimates are needed for each and every crop $(6+6=12)$. The full steps to estimates those matrices are illustrated bellow:

In the first stage of estimating parameters, Forecasted Average yield “ $y_{f j}$ ” using actual yields for Maize, Rice, Beans, Cassava, Irish Potatoes, and Farmers Appraisal on weather condition was computed as follow:

$$
y_{f j}=\frac{\sum_{i=1}^{4} y_{i j} \omega_{i j} c_{i k}}{\sum_{i=1}^{4} \omega_{i j} c_{i k}}
$$

Where $\omega_{i j}=y_{i j} * p_{i j}$ with $p_{i j}=\frac{y_{i j}}{\sum_{i=1}^{4} y_{i j}}$

Where $y_{i}=\{1,2,3,4 \mid$ yield values for four percentiles dividing actual yields into five equal groups $\}$ for crop “ $j "$ with $j=$ $\{$ Crops $\mid$ Maize, Rice, Wheat, Beans, Cassava, and Irish Potatoes $\}, k=\left\{\right.$ Poor, Fair, Good, Very Good $\mid C_{k}=$ Weather Condition $\}$; and $\omega_{i j}=$ expected yield in each category for crop " $j$ ". Weather Conditions " $C_{i k}$ " are associated with Actual yield $y_{i j}$ by $C_{i k}$ with $\left\{C_{i k}=\{1=\right.$ Poor, $2=$ Fair, $3=$ Good, $4=$ Very Good $\mid i$ percentile is linked with its corresponding $k$ weather condition $\}$.

In the second stage, actual performance to reach yield targets for each crop " $j$ " " $R_{j}$ " is computed basing on $y_{f j}=$ Forecasted Yield for Crop $(j)$ and $Y_{t j}=$ Yield Target for $(j)$ :

$$
R_{j}=\frac{y_{f j}}{y_{t j}}
$$

In the third stage, $Y_{f j}$ and their associated reliabilities (in this paper reliability was assigned to be High Medium " $H M=3 \%$ " 
and Medium " $M=6 \%$ ") were used to estimate Variance Matrix $\left(E_{1}\right)$; while $Y_{t j}, R_{j}$, and their associated reliabilities were used to estimate Covariance Matrix $(H)$. Matrix D was estimated using Identity Matrix (6x6) of 6 Six crops used in this paper and Zero Matrix (6x6) of forecasted Yield for six crop therefore $D_{6 \times 12}=\left(I_{6 \times 6} 0_{6 \times 6}\right)$, the column matrix $\left(d_{6 \times 1}\right)$ of Laboratory yield.

Assuming that " $d_{l} \mid x^{l} \sim N_{p}\left(D_{l} x^{l} \Sigma_{l}\right)$ where $D_{l,(p ; n)}$ has full row-rank and $\Sigma_{l}$ is positive definite (hence non-singular); (ii) $A x^{l} \sim$ $N_{m}(h ; H)$ where $A=(A 1: A 2)$, a column vector $h=\left(h_{1} ; h_{2}\right)$; a block diagonal matrix $H=(H 1 ; H 2)$ with $H_{1}$ associated with $A_{l}$ and $\mathrm{H}_{2}$ with $A_{2}$; (iii) $A$ has full row- rank and $H$ may be singular. Then the posterior distribution of $x^{l}$ is given by $\mathrm{x}^{1} \mid d_{l} \sim N_{n}(\mu$; V )" with:

$$
\left.\mu=\left(A^{+} H A^{+T}\right) D^{T} \Sigma^{-1} d_{1}\right)
$$

and

$$
V=A^{+} H A^{+T}-A^{+} H A^{+T} D^{T} \Sigma^{-1} D 1 A^{+} H A^{+T}
$$

Where $A^{+}=A^{T}\left(A A^{T}\right)^{-1}$ "the Moore-Penrose inverse", and

$$
\Sigma_{0}=\Sigma_{1}+D 1 A^{+} H A^{+T} D^{T}
$$

\section{Description of data}

Crop Yields 2002 - 2012 (22 Agricultural Seasons)

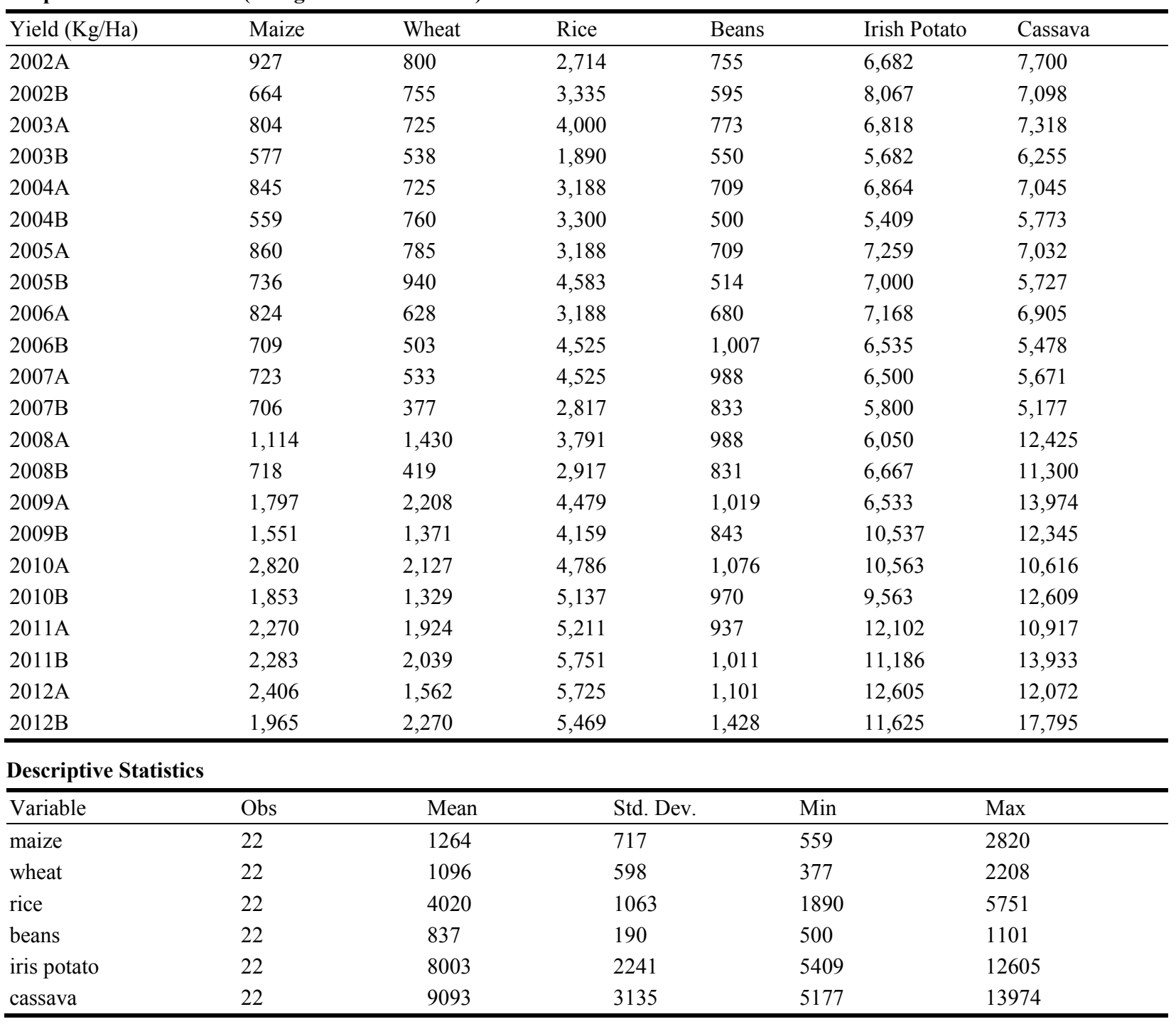




\begin{tabular}{|c|c|c|c|c|c|c|c|}
\hline & Cut-of & $Y_{i j}$ & $p_{i j}$ & $Q_{i j}$ & $C_{i k}$ & $Y_{i j} C_{i j} C_{i k}$ & $Q_{i j} C_{i k}$ \\
\hline \multirow{4}{*}{ Maize Percentiles } & 20 & 708 & 0.15 & 107 & 0.476 & 36,077 & 51 \\
\hline & 40 & 808 & 0.17 & 139 & 0.247 & 27,818 & 34 \\
\hline & 60 & 1077 & 0.23 & 248 & 0.148 & 39,489 & 37 \\
\hline & 80 & 2087 & 0.45 & 931 & 0.128 & 248,604 & 119 \\
\hline \multirow{4}{*}{ Wheat Percentiles } & 20 & 536 & 0.12 & 64 & 0.476 & 16,201 & 30 \\
\hline & 40 & 756 & 0.17 & 127 & 0.247 & 23,639 & 31 \\
\hline & 60 & 1252 & 0.28 & 347 & 0.148 & 64,283 & 51 \\
\hline & 80 & 1970 & 0.44 & 860 & 0.128 & 216,844 & 110 \\
\hline \multirow{4}{*}{ Rice Percentiles } & 20 & 3079 & 0.19 & 586 & 0.476 & 858,479 & 279 \\
\hline & 40 & 3426 & 0.21 & 725 & 0.247 & 613,516 & 179 \\
\hline & 60 & 4516 & 0.28 & 1260 & 0.148 & 841,942 & 186 \\
\hline & 80 & 5167 & 0.32 & 1649 & 0.128 & $1,090,556$ & 211 \\
\hline \multirow{4}{*}{ Beans Percentiles } & 20 & 646 & 0.19 & 123 & 0.476 & 37,696 & 58 \\
\hline & 40 & 784 & 0.23 & 181 & 0.247 & 34,970 & 45 \\
\hline & 60 & 963 & 0.28 & 272 & 0.148 & 38,816 & 40 \\
\hline & 80 & 1014 & 0.30 & 302 & 0.128 & 39,194 & 39 \\
\hline \multirow{4}{*}{ Irish Potato Percentiles } & 20 & 6320 & 0.20 & 1285 & 0.476 & $3,865,861$ & 612 \\
\hline & 40 & 6709 & 0.22 & 1448 & 0.247 & $2,399,805$ & 358 \\
\hline & 60 & 7241 & 0.23 & 1687 & 0.148 & $1,807,711$ & 250 \\
\hline & 80 & 10812 & 0.35 & 3761 & 0.128 & $5,205,257$ & 481 \\
\hline \multirow{4}{*}{ Cassava Percentiles } & 20 & 5755 & 0.16 & 916 & 0.476 & $2,508,073$ & 436 \\
\hline & 40 & 7056 & 0.20 & 1377 & 0.247 & $2,399,246$ & 340 \\
\hline & 60 & 10857 & 0.30 & 3259 & 0.148 & $5,236,726$ & 482 \\
\hline & 80 & 12499 & 0.35 & 4319 & 0.128 & $6,910,351$ & 553 \\
\hline
\end{tabular}

\section{Model Estimation}

Estimation of Matrix D

\begin{tabular}{|c|c|c|c|c|c|c|c|c|c|c|c|}
\hline Maize & Rice & Wheat & Beans & Cassava & $\begin{array}{l}\text { Irish } \\
\text { Potatoes }\end{array}$ & MaizeF & RiceF & WheatF & BeansF & CassavaF & $\begin{array}{l}\text { Irish } \\
\text { PotatoesF }\end{array}$ \\
\hline 1 & 0 & 0 & 0 & 0 & 0 & 0 & 0 & 0 & 0 & 0 & 0 \\
\hline 0 & 1 & 0 & 0 & 0 & 0 & 0 & 0 & 0 & 0 & 0 & 0 \\
\hline 0 & 0 & 1 & 0 & 0 & 0 & 0 & 0 & 0 & 0 & 0 & 0 \\
\hline 0 & 0 & 0 & 1 & 0 & 0 & 0 & 0 & 0 & 0 & 0 & 0 \\
\hline 0 & 0 & 0 & 0 & 1 & 0 & 0 & 0 & 0 & 0 & 0 & 0 \\
\hline 0 & 0 & 0 & 0 & 0 & 1 & 0 & 0 & 0 & 0 & 0 & 0 \\
\hline
\end{tabular}

Estimation of Variance Matrix (E Matrix)

\begin{tabular}{lllll}
\hline Crops & Mean & Reliability & $\begin{array}{l}\text { PrioSev= } \\
\text { Mean * Re }\end{array}$ & $\begin{array}{l}\text { PrioV }= \\
\text { PrioSe }^{2}\end{array}$ \\
\hline Maize & 1260 & 0.01 & 13 & 159 \\
Wheat & 1125 & 0.05 & 56 & 3164 \\
Rice & 4031 & 0.05 & 202 & 40622 \\
Beans & 855 & 0.05 & 43 & 1828 \\
Irish Potato & 8055 & 0.05 & 403 & 162208 \\
Cassava & 9326 & 0.05 & 466 & 217436 \\
\hline
\end{tabular}

Estimated Variance Matrix

\begin{tabular}{llllll}
\hline Maize & Wheat & Rice & Beans & Irish Potato & Cassava \\
\hline 159 & 0 & 0 & 0 & 0 & 0 \\
0 & 3164 & 0 & 0 & 0 & 0 \\
0 & 0 & 40622 & 0 & 0 & 0 \\
0 & 0 & 0 & 1828 & 0 & 0 \\
0 & 0 & 0 & 0 & 162208 & 0 \\
0 & 0 & 0 & 0 & 0 & 217436 \\
\hline
\end{tabular}


Estimation of covariance Matrix (H Matrix)

\begin{tabular}{lllllllll}
\hline & Yfj & Ytj & Pi & Reability & PrioSe & PrioV & $\mathrm{Bij}^{\wedge} 2$ & ${\text { PrioV } * \mathrm{Bij}^{\wedge} 2}^{213}$ \\
\hline Maize & 1,459 & 3750 & 0.39 & 0.01 & 0.004 & 0.0000 & 14062500 & 5181 \\
Wheat & 1,440 & 3500 & 0.41 & 0.05 & 0.021 & 0.0004 & 12250000 & 39600 \\
Rice & 3,980 & 7000 & 0.57 & 0.05 & 0.028 & 0.0008 & 49000000 & 1716 \\
Beans & 829 & 1850 & 0.45 & 0.05 & 0.022 & 0.0005 & 3422500 & 152446 \\
Irish Potato & 7,809 & 27500 & 0.28 & 0.05 & 0.014 & 0.0002 & 756250000 & 221679 \\
Cassava & 9,417 & 35000 & 0.27 & 0.05 & 0.013 & 0.0002 & 1225000000 & \\
\hline
\end{tabular}

Estimated Covariance Matrix

\begin{tabular}{llllllllllll}
\hline Maize & Wheat & Rice & Beans & $\begin{array}{l}\text { Irish } \\
\text { Potato }\end{array}$ & Cassava & MaizeF & WheatF & RiceF & BeansF & $\begin{array}{l}\text { Irish } \\
\text { PotatoF }\end{array}$ & CassavaF \\
\hline 213 & 0 & 0 & 0 & 0 & 0 & 0 & 0 & 0 & 0 & 0 & 0 \\
0 & 5181 & 0 & 0 & 0 & 0 & 0 & 0 & 0 & 0 & 0 & 0 \\
0 & 0 & 39600 & 0 & 0 & 0 & 0 & 0 & 0 & 0 & 0 & 0 \\
0 & 0 & 0 & 1716 & 0 & 0 & 0 & 0 & 0 & 0 & 0 & 0 \\
0 & 0 & 0 & 0 & 152446 & 0 & 0 & 0 & 0 & 0 & 0 & 0 \\
0 & 0 & 0 & 0 & 0 & 221679 & 0 & 0 & 0 & 0 & 0 & 0 \\
0 & 0 & 0 & 0 & 0 & 0 & 0 & 0 & 0 & 0 & 0 & 0 \\
0 & 0 & 0 & 0 & 0 & 0 & 0 & 0 & 0 & 0 & 0 & 0 \\
0 & 0 & 0 & 0 & 0 & 0 & 0 & 0 & 0 & 0 & 0 & 0 \\
0 & 0 & 0 & 0 & 0 & 0 & 0 & 0 & 0 & 0 & 0 & 0 \\
0 & 0 & 0 & 0 & 0 & 0 & 0 & 0 & 0 & 0 & 0 & 0 \\
0 & 0 & 0 & 0 & 0 & 0 & 0 & 0 & 0 & 0 & 0 \\
\hline
\end{tabular}

Estmation of A Matrix (Pi)

\begin{tabular}{|c|c|c|c|c|c|c|c|c|c|c|c|}
\hline Maize & Rice & Wheat & Beans & Cassava & $\begin{array}{l}\text { Irish } \\
\text { Potatoes }\end{array}$ & MaizeF & RiceF & WheatF & BeansF & CassavaF & $\begin{array}{l}\text { Irish } \\
\text { PotatoesF }\end{array}$ \\
\hline-0.39 & 0 & 0 & 0 & 0 & 0 & 1 & 0 & 0 & 0 & 0 & 0 \\
\hline 0 & -0.41 & 0 & 0 & 0 & 0 & 0 & 1 & 0 & 0 & 0 & 0 \\
\hline 0 & 0 & -0.57 & 0 & 0 & 0 & 0 & 0 & 1 & 0 & 0 & 0 \\
\hline 0 & 0 & 0 & -0.45 & 0 & 0 & 0 & 0 & 0 & 1 & 0 & 0 \\
\hline 0 & 0 & 0 & 0 & -0.28 & 0 & 0 & 0 & 0 & 0 & 1 & 0 \\
\hline 0 & 0 & 0 & 0 & 0 & -0.27 & 0 & 0 & 0 & 0 & 0 & 1 \\
\hline-1 & 0 & 0 & 0 & 0 & 0 & 1 & 0 & 0 & 0 & 0 & 0 \\
\hline 0 & -1 & 0 & 0 & 0 & 0 & 0 & 1 & 0 & 0 & 0 & 0 \\
\hline 0 & 0 & -1 & 0 & 0 & 0 & 0 & 0 & 1 & 0 & 0 & 0 \\
\hline 0 & 0 & 0 & -1 & 0 & 0 & 0 & 0 & 0 & 1 & 0 & 0 \\
\hline 0 & 0 & 0 & 0 & -1 & 0 & 0 & 0 & 0 & 0 & 1 & 0 \\
\hline 0 & 0 & 0 & 0 & 0 & -1 & 0 & 0 & 0 & 0 & 0 & 1 \\
\hline \multicolumn{12}{|c|}{ Estimation of dT Matrix } \\
\hline & \multicolumn{2}{|c|}{ Maize } & \multicolumn{2}{|c|}{ Rice } & \multicolumn{2}{|l|}{ Wheat } & Beans & \multicolumn{2}{|c|}{ Cassava } & \multicolumn{2}{|c|}{ Irish Potatoes } \\
\hline$Y_{f j}$ & \multicolumn{2}{|r|}{1,459} & \multicolumn{2}{|c|}{1,440} & \multicolumn{2}{|l|}{3,980} & 829 & \multicolumn{2}{|c|}{7,809} & \multicolumn{2}{|c|}{9,417} \\
\hline
\end{tabular}

